\title{
"Guessing at our Mental Models" or "Committed Knowing Acts"-What are our Students Doing?
}

\author{
RACHEL QUINLAN
}

\begin{abstract}
This article proposes a discussion of the goals, effectiveness, and shortcomings of Mathematics curricula and assessment systems in higher education. Selected writings by mathematicians, mathematics educationalists and higher education theorists on the broad themes of curriculum and assessment are cited as points of reference. The relationship (or disaffection) between the academic communities of practitioners and theorists in these areas is briefly considered.
\end{abstract}

\section{INTRODUCTION}

Extensive analysis, commentary and theory (and occasional counsel) on the subject of the teaching and learning of mathematics at third level can be found in the Mathematics Education research literature. Casual perusal of the tables of contents of such journals as Journal of Mathematical Behaviour, Educational Studies in Mathematics and Research in Mathematics Education (to name just three examples) confirms that both the teaching practices of mathematicians and the learning practices of mathematics students command the attention of a busy and populous research community that is geographically widespread and ideologically diverse. This community, while not entirely disjoint from the academic research community in mathematics, stands mostly apart from it.

Further theory and commentary about such matters as instruction at third level and the goals and purposes of tertiary education can be found in the academic literature on Higher Education. Some of this may be of interest and value to lecturers trying to instigate and support a meaningful and stimulating intellectual experience for students while operating in an environment that is ever more 
constrained, for example by inflexible institutional assessment regulations and by severe resource limitations.

The meaning of the term "curriculum" does not appear to be consistent throughout educational discourse. In this article, the term is intended to include every aspect of the student's encounter with the subject that is part of the programme of study. It includes the syllabus, which typically consists of a list of topics to be studied. It includes all lectures, tutorials, workshops, laboratory sessions and other scheduled classroom events. It includes all the resources that the students are invited to utilize, such as the library and interaction with the academic staff. It includes the tasks that are assigned for students to do, including summative assessment, and it includes the styles of thinking and investigation that have to be employed in order to complete these tasks. It includes all the activities that the students are advised, instructed or otherwise prompted to engage in, which over the course of a mathematics degree might involve such examples as

- practising the implementation of procedures (for example Gaussian elimination);

- writing a computer programme to automate such implementation (for example to apply the Euclidean algorithm);

- studying, and writing on, selected topics from the modern mathematical canon;

- participating as a team member in a mathematical modelling project;

- memorizing tracts of lecture notes for reproduction in an exam;

- assessing the validity and significance of a proof;

- investigating a phenomenon, proposing a conjecture, writing a proof.

In their book "Engaging the Curriculum in Higher Education" 2], Ronald Barnett and Kelly Coate comment on the relative responsibilities of the student and instructor in realizing the curriculum. They argue that if a curriculum is considered to be more than "a set of educational processes that is simply presented to a student", then the responsibility for realizing this curriculum rests with the student as well as with the instructors and institution. They point out however that the curriculum experienced by the student, while its character depends in great measure on the student's engagement, 
disposition and willingness to assume responsibility, is nevertheless delineated by the curriculum that is presented by lecturers.

The curriculum as presented opens up educational possibilities on the one hand and limits educational possibilities on the other. It contains choices, whether explicit or tacit, that constrain the educational experience available to the student.

A central theme of the book by Barnett and Coate is their conceptualization of curriculum in terms of the student's experience in three distinct but intertwined domains that they refer to as knowing, acting, and being. Their use of these verbal forms is deliberate, intended to emphasize the critical role of the student's conscious and purposeful agency. Knowledge, they suggest, "has come to be conceived as consisting of a corpus - of ideas, proposition, theories, concepts that stand outside students". The image of a knowledge corpus to be understood and assimilated is contrasted with the idea of the student engaging in "committed knowing acts":

an act of knowing is just that: an act. It calls for will, an act of identity and a claim to ownership . . . individuals mark themselves out, project themselves, and claim themselves to be here rather than there. An act of knowing is a positional and personal act.

\section{What DO WE ASSERT THAT OUR CURRICULA ARE FOR?}

Answers to this question may obviously vary across institutions, programmes and individuals. Nevertheless, a casual search for statements by unversity mathematics units of objectives and learning outcomes of their degree programmes returns many recurrent themes. One place to which we might turn in search of a general or representative answer from the mathematics community to this question is to the work of the Mathematics work group of the "Tuning Educational Structures in Europe" project. The Tuning Project was established in 2000 with the goal of connecting the political objectives of the 1999 Bologna Declaration (such as "Adoption of a system of easily readable and comparable degrees") to institutions of higher education and to educational structures, at the subject level. Mathematics was one of nine subject areas considered in Phases I and II of Tuning, which was a pilot project running from 2000 to 2004 . Although the inception and development of this project was linked to the Bologna 
Process, it was an academic project rather than a political one : its participants were groups of academics within subject areas, whose tasks included "developing reference points for common curricula on the basis of agreed competences and learning outcomes as well as cycle level descriptors". The Mathematics group included 14 academic mathematicians from 14 European countries, and its outputs included a "Summary of Outcomes" document that is available on the Tuning webpages [10, and a discussion document entitled "Towards a common framework for Mathematics degree in Europe" [6], which appeared in the Newsletter of the European Mathematical Society in 2002. The point here is not to comment on the Bologna or Tuning projects but to suggest that the contents of these documents, arising from the discussions of a group of mathematicians assembled from different institutions and countries and from their wider consultations with colleagues, might be reasonably construed as reflecting "typical" views of mathematicians on what mathematics curricula should aim to achieve.

Both documents identify the following "key skills" that "may be expected of any mathematics graduate":

- the ability to conceive a proof;

- the ability to model a situation mathematically;

- the ability to solve problems using mathematical tools.

The "Summary of Outcomes" document also proposes the following descriptors for students graduating with a primary degree in Mathematics; these were identified following a survey of the views of a wider group of academics.

Students will be able to

- show knowledge and understanding of basic concepts, principles, theories and results of mathematics;

- understand and explain the meaning of complex statements using mathematical notation and language;

- demonstrate skill in mathematical reasoning, manipulation and calculation;

- construct rigourous proofs;

- demonstrate proficiency in different methods of mathematical proof. 
These expectations seem to be generally consistent with statements made by institutions and their mathematics units on learning outcomes, objectives, and value of their primary degree programmes in mathematical subjects. A quick search returned the following items and many others of a similar nature. The specific items listed below come from six universities in four predominantly English speaking countries including Ireland.

- [Graduates will be able to] demonstrate in-depth knowledge of Mathematics, its scope, application, history, problems, methods, and usefulness to mankind both as a science and as an intellectual discipline.

- [You will learn] how to analyse and solve problems of a quantitative nature and to communicate the results clearly.

- [You will have the] ability to follow complex mathematical arguments and to develop mathematical arguments of your own.

- The increased analytical ability, comprehension of abstract concepts and creative thinking that you gain from studying mathematics are highly valued in the business, industrial, social and academic worlds.

- Graduates will have] proficiency in the comprehension and writing of mathematical proofs. They will be able to write well-organized, grammatically correct, and logically sound mathematical arguments.

- [Students will have the opportunity to develop the ability] to think critically about solutions and to defend an intellectual position.

These extracts are selected from a scattered assortment of sources, and are unlikely to have any special relevance for any department or programme. However such themes as "analytical thinking", "reasoning with abstract concepts", "proficiency with proof", "usefulness", "creative thinking", "communication of mathematical ideas" and "problem solving" seem to be widely recurrent in statements made by higher education institutions in advertising their programmes to prospective students and in communicating their expectations to current students. Experience shows that abilities of these sorts are not easily learned, not easily taught and not easily assessed. Our expectations of ourselves and our students are high, if we are serious about presenting a curriculum that will both demand and support 
thinking that is variously or simultaneously rigourous, complex, abstract, creative, useful and effective for communicating ideas. What students need in order to achieve such learning is described by the mathematics education theorist David Tall in [13] in the following terms :

What is essential [for students] is an approach to mathematical knowledge that grows as they grow: a cognitive approach that takes account of the development of their knowledge structure and thinking processes. To become mature mathematicians at an advanced level, they must ultimately gain insight into the ways of advanced mathematicians but, en route, they may find a stony path that will require a fundamental transition in their thinking processes.

Curriculum is the mechanism through which all of this is supposed to be achieved. Assessment is the means by which the success of the individual student's engagement with the curriculum is supposed to be measured.

\section{SOME QUESTIONS}

The following quotation, from the essay "On proof and progress in mathematics" [14, by the geometer and Fields medallist William Thurston, is proposed as a focal point for a discussion about the reality of our curricula. Thurston's widely cited article first appeared in the Bulletin of the American Mathematical Society in 1994, and was republished in 2006 in the volume "18 Unconventional Essays on the Nature of Mathematics", edited by Reuben Hersh. Positing that the business of mathematicians is "to advance human understanding of mathematics", Thurston asks (as part of a wider discussion) "How is mathematical understanding communicated?". His answer includes the assertion that communication of technical mathematical ideas particular to a narrow research specialization is remarkably efficient and reliable among expert practitioners in that specialization. However, he also charges that communication across subdisciplinary boundaries or to more general (mathematical) audiences is "often dysfunctional", citing experiences of colloquium talks where "most of the audience" is "lost within the first 5 minutes". The following is what he has to say about what happens in classrooms. 
This pattern is similar to what often holds in classrooms, where we go through the motions of saying for the record what we think the students 'ought' to learn, while the students are busy with the more fundamental issues of learning our language or guessing at our mental models. Books compensate by giving samples of how to solve every type of homework problem. Professors compensate by giving homework and tests that are much easier than the material 'covered' in class, and then grading the homework and tests on a scale that requires little understanding. We assume that the problem is with the students rather than with communication: that the students either just don't have what it takes, or else just don't care.

Outsiders are amazed at this phenomenon, but within the mathematical community, we dismiss it with shrugs.

This is not a flattering description of our curricula in action, either as experienced by students or as presented by lecturers. It is offered as a general description of what "often holds", not as a comment about individual lecturers or individual students. It is doubtful whether an international community of practitioners of mathematical instruction at third level really exists (although this may eventually change, for example as the Bologna process rolls on). Our practice in the educational area of our work is organized within local structures; discussion of educational issues within subjects does not necessarily carry easily across institutional or national boundaries. However, the existence of a genuine worldwide community of research in the mathematical sciences can be reasonably asserted. Members of this community collaborate on research projects, they run societies and journals, they gather at conferences and they maintain and share repositories such as Mathematical Reviews. The members of this research community are, by and large, the same people who are responsible for the design and operation of mathematics curricula in the world's institutions of higher education. By referring to "the mathematical community", Thurston lays his charge squarely at all of our doors. As mentioned in the introduction and again in Section 4 below, critical scrutiny of our collective performance as educators 
seems to be an activity more often located outside our community than within it (at least if we are to judge from research literature on the subject). Thurston's charge however is levelled from within. How would we answer it, if we had to? Here are some questions.

(1) Is Thurston's description accurate?

(2) If not, how can we refute it? Would our refutation satisfy an "outsider amazed at this phenomenon" if such persons exist as alleged?

(3) If the answer to Question 1 is (partly) yes, is this ok?

(4) If so, how can we justify it?

(5) If our answer to Question 3 is no, we would much prefer if things were different, can we change the situation? What would we need? What would it take?

One pedagogical tool that is cited and used by many practitioners and theorists in higher education is the model of constructive alignment proposed by the Australian educational psychologist John Biggs [5. This model is founded on the premise that what the student learns depends more on what the student does than on what the instructors do or on any other factor. It is widely accepted also that "from the students' point of view, assessment always defines the actual curriculum" [11. So : if assessment determines what students do, and what students do determines what students learn, Biggs basically proposes a deliberate and visible alignment of assessment tasks, learning activities and learning outcomes, so that the activities in which students are prompted to engage by the threat/promise of impending assessment are activities that cannot avoid addressing the learning outcomes. This summary description of Biggs's model may appear at first glance to come straight from the "stating the obvious and giving it a name" school of pedagogical theory, but at least two observations can be made. First, the idea of constructive alignment calls for a shift of attention from syllabus content and assessment requirements to what the student does, and it calls for explicit attention to and emphasis on learning outcomes, but "more as a function of students' activities than of their fixed characteristics" [5]. Second, what Thurston seems to be describing is a pattern of curriculum in action that is (in his view) not aligned in the sense of Biggs. According to his description, statements of supposed learning outcomes are offered in a tone more of resignation than (even) aspiration, with a 
sense of "going through the motions". Meanwhile, students and instructors alike are complicit in a spoken or unspoken understanding about how the assessment will operate, with the result that what students do is imitate worked examples from an exhaustive supply. Similar general observations have been made by many authors. A 2007 study 4 of 16 examination papers from calculus courses in four Swedish universities found that $70 \%$ of the examination tasks could be completed using only "imitative reasoning" and that 15 of the papers could be passed using only reasoning of this kind. Michèle Artigue comments in [1] that

A good number of scholastically well-adapted students succeed, including at the university, more by learning to decode the terms of the didactic contract and by conforming to it than by really learning mathematics . . . it is not easy to construct learning situations where we can ensure that students' success implies real mathematical engagement.

It is my opinion that if we wanted to assemble a case for a negative answer to Question 1 above, we would have no difficulty finding compelling evidence. We are all involved in many examples of courses where the evident patterns of instruction and student activity bear little resemblance to Thurston's description and are demonstrably connected to the graduate attributes described in Section 2, The prosecution might argue though that such courses are more typical of the later stages of degree programmes, by which point few of the students from the first year class remain, most having opted for another path after perhaps being alienated by experiences of the nature described by Thurston.

The environment in which our curricula operate is limited and constrained in many ways. In most of our institutions, we have no choice but to teach our first year students in large groups, in which attention to each student's pace of progress along Tall's "stony path" is just not possible. Funding for such supports as part time teaching is being cut at a time when our students are more numerous and their needs more diverse than ever before. Modularized programmes oblige us to package our subjects into compact and separate chunks, primarily and probably unavoidably along syllabus lines. Another feature of modularization is that summative assessment is frequent 
and also highly compartmentalized, with examination papers typically corresponding to courses of 24 or 36 lectures that take place over only 12 weeks. Insistent reliance on old exam papers appears to be a deeply ingrained feature of Irish students' behaviour, especially in the early years of their third level education. Radical departure from tradition in assessment practice is not always an appealing prospect for lecturers, no matter how sincere their desire to improve the quality of learning. It's a risky business and the consequences of failure are serious, for students and for us. Our teaching work frequently involves a negotiation of many institutional and disciplinary priorities and pressures, and tensions between them. We are competing against other disciplines for students. We want to know that our curricula are effective at developing such sweeping attributes as "creative mathematical thinking", but we have to assess our students' learning on a compartmentalized basis, and in a pressurized environment that is very different from the one in which our own mathematical creativity primarily finds expression.

\section{Can Research in Mathematics Education help?}

The question of whether research in Mathematics Education can help individual lecturers faced with specific teaching challenges is separate from the question of whether the Mathematics Education research community can help the community of mathematics lecturers with its task of designing and delivering effective curricula. The first question, obviously, is for any lecturer who feels so inclined to investigate for himself or herself: different lecturers who do so may reach different conclusions. There are no theorems in Mathematics Education. The Winter 2002 issue of this bulletin contains an account [7] by Maria Meehan of how consultation of the Mathematics Education research literature can help a lecturer to develop insight into the nature and causes of apparent obstacles to student learning. Lecturers contemplating potential or actual difficulties in the teaching and learning of specific syllabus items may find in this literature a useful strategy, a perceptive discussion of the problem, or at least an assurance that the difficulty is not imagined or invented. The 1991 volume Advanced Mathematical Thinking [13] challenged what I thought I understood about how people learn our subject and persuaded me that Mathematics Education research has something of interest to say. 
On the second question above, opinion seems to be divided. A considerable amount has been written on the subject of the relationship between the Mathematics and Mathematics Education research communities (see, for example, Part VI of [12]). A strong advocate for a strengthening of this relationship is the American algebraist Hyman Bass, who makes the following argument in 3 .

The emergence of a highly competitive and technological world economy has fundamentally enlarged the demands on mathematics education. We now seek, for the broad workforce, levels of scientific and technical competence and literacy that approach what was formerly deemed appropriate only for a select and specialized student population . . . When large numbers of students fail and/or leave mathematical study, which is the gateway to such competence and literacy, this is judged now to be the failure - not of the students - but of the educational system.

Bass goes on to propose that a reconsideration by mathematical scientists of their role as educators is needed, and he argues for programmes of professional development of academic mathematicians as teachers, with the mentorship of "education professionals". He concedes that this is not a popular view in the academic mathematical community and "is not an easy proposition", but argues

Much remains to be done to establish contexts for respectful communication and professional collaboration between mathematical scientists and education professionals. . . . This is ultimately a two-way street, along which mathematical scientists can contribute to the disciplinary strengthening of school programs and teaching practice, while the teacher and education research communities can elevate the pedagogical consciousness and competence of academic mathematical scientists.

It hardly needs to be said that not every academic mathematician shares the conviction of Bass on the potential impact and mutual benefit of a closer alliance between the two communities. For balance (or at least opposition), here is the view of another prominent algebraist, Shimshon Amitsur. These words are from an interview 
with the mathematics educationalist Anna Sfard, carried out in 1994 and documented in 12 .

To strengthen the status of research in mathematics education, one has to prove its usefulness. The onus of proof is on the researchers themselves. They have to show that they have a theory of mathematical thinking which convincingly explains observed phenomena. Only when they can provide such a theory will mathematics education turn into a true academic discipline. Not even one day earlier.

More recently, the UK-based mathematics educationalist Elena Nardi has written extensively on what she refers to as "the often difficult relationship between the communities of mathematics and mathematics education". Her 340-page book "Amongst Mathematicians" 8], which appeared in 2008, is a study of teaching and learning of mathematics at undergraduate level, based on a wide range of written and audio data from both lecturers and students and supported by the author's professed "fundamental underlying belief" that "development in the practice of university-level mathematics teaching is manageable, and sustainable, if driven and owned by the mathematicians who are expected to implement it". In a related work 9, Nardi and Paola Iannone report on a study of the views of 20 research mathematicians on the relationship, and its potential, between the two communities. While the strong call for collaboration in these works and others may well be echoed by many mathematicians, 8 and 9 seem to be cooperative rather than truly collaborative projects. They are studies of the attitudes and practices of members of one community, by members of the other. While the "two-way street" envisaged by Bass is a notion with obvious appeal, it remains to be seen whether the "fragile, crucial" relationship discussed in [9] can evolve into a genuine partnership.

\section{REFERENCES}

[1] Michèle Artigue. The teaching and learning of mathematics at the university level. Notices of the AMS, 46(11), 1999.

\footnotetext{
${ }^{1}$ Amitsur died in 1994 , so we cannot know whether he would consider that mathematics education has yet attained the status of a "true academic discipline". His remarks quoted here are roughly contemporary with those of Bass.
} 
[2] Ronald Barnett and Kelly Coate. Engaging the Curriculum in Higher Education. Open University Press, 2005.

[3] Hyman Bass. Mathematicians as educators. Notices of the AMS, 44(1):1821, 1997.

[4] Ewa Bergqvist. Types of reasoning required in university exams in mathematics. Journal of Mathematical Behaviour, 26:348-370, 2007.

[5] John Biggs. What the student does : teaching for enhanced learning. Higher Education Research and Development, 18(1):57-75, 1999.

[6] Tuning Mathematics Group. Towards a common framework for mathematics degrees in europe. Bulletin of the European Mathematical Society, 45, 1992.

[7] Maria Meehan. Students meeting advanced mathematics for the first time: can mathematics education research help? Bulletin of the Irish Mathematical Society, 49:71-82, 2002.

[8] Elena Nardi. Amongst Mathematicians. Springer, 2008.

[9] Elena Nardi and Paola Iannone. On the fragile, yet crucial, relationsip between mathematicians and researchers in mathematics education. Proceedings of the 28th Conference of the International Group for the Psychology of Mathematics Education, 2004.

[10] Tuning Project. http://tuning.unideusto.org/tuningeu/.

[11] Paul Ramsden. Learning to Teach in Higher Education. Routledge, 1992.

[12] Anna Sierpinska and Jeremy Kilpatrick, editors. Mathematics Education as a Research Domain : a Search for Identity. Kluwer Academic Publishers, 1998.

[13] David Tall, editor. Advanced Mathematical Thinking. Kluwer, 1991.

[14] William P. Thurston. On proof and progress in mathematics. Bulletin of the AMS, 30(2):161-177, 1994.

Rachel Quinlan,

Department of Mathematics,

National University of Ireland,

Galway, Ireland

rachel.quinlan@nuigalway.ie

Received on 30 November 2010. 